\title{
Is concept mapping favourable for undergraduates with different learning styles?
}

\author{
Julia S.W. Wong*1, Baaska Anderson ${ }^{2}$, Martin Gough ${ }^{2}$ \\ ${ }^{1}$ School of Nursing, Tung Wah College, Hong Kong, China \\ ${ }^{2}$ University of Liverpool, Liverpool, United Kingdom
}

Received: June 11, 2020

Accepted: August 7, 2020

Online Published: August 17, 2020

DOI: $10.5430 /$ jnep.v10n12p7

URL: https://doi.org/10.5430/jnep.v10n12p7

\begin{abstract}
Background and objective: Concept mapping is a powerful metacognition and visual learning tool. However, human beings are born to understand and perceive the world using five basic senses. According to Neil Fleming's VARK model, there are five different types of sensory modality groups which include visual, auditory, read/write, kinaesthetic and mixed modality. Therefore, this study aimed to investigate the effects of CM on students' overall academic performance among visual, auditory, read/write, kinaesthetic and multi-modal dominant learners.

Methods: This was a cross-sectional quantitative research study. The participants were nursing undergraduates in a private higher education institute and enrolled in the same course offered in the spring and summer semesters. At the beginning of the semester, the VARK questionnaire version 7.8 was used to identify students' sensory modality groups. Concept mapping was adopted for teaching the course. After the semester, students' overall academic performance was used to compare the differences between different sensory modality groups.

Results: The mean grades of the spring students were: visual $(M=80.80, S D=7.30)$, aural $(M=81.49, S D=4.19)$, read/write $(M=81.16, S D=8.69)$, kinaesthetic $(M=78.27, S D=7.56)$ and multimodal $(M=79.56, S D=7.65)$. The means grade of summer students were: visual $(M=74.68, S D=8.59)$, aural $(M=78.79, S D=9.38)$, read/write $(M=74.89, S D=3.87)$, kinaesthetic $(M$ $=77.10, S D=9.69)$ and multimodal $(M=75.96, S D=9.74)$. After comparing the average grades between different sensory modality groups in both spring and summer semesters using One-way ANOVA testing, there were no statistically significant differences found.

Conclusions: The results of this study show that teaching with animated CM in PowerPoints and co-construction of CM seems to be applicable to learners with different sensory modality groups.
\end{abstract}

Key Words: Concept mapping, Nursing education, VARK model, Learning style

\section{BACKGROUND}

Concept mapping (CM) was developed by Joseph Novak in 1972, which was based on David Ausubel's Assimilation Theory (1963) ${ }^{[1]}$ of meaningful learning and the concept of constructivism and scaffold learning. ${ }^{[2]} \mathrm{CM}$ is 'a two-dimensional schematic device for representing a set of concept meanings embedded in a framework of propositions' (p. 15) ${ }^{[3]}$ and structured in a hierarchical form. It creates meaningful and visible learning by linking up the relationships between concepts with arrows and connective words. ${ }^{[4]}$ Many research studies have revealed that it is a powerful metacognition and visual tool which promotes active learn-

\footnotetext{
*Correspondence: Julia S. W. Wong; Email: juliawong@twc.edu.hk; Address: School of Nursing, Tung Wah College, 31 Wylie Road, Homantin, Hong Kong, China. 
ing and enhances students' understanding of complicated knowledge, critical thinking and problem-solving skills, and promotes a positive learning experience. ${ }^{[5-8]}$ Furthermore, it seems quite effective for learners across different healthcare contexts in higher education, such as nursing, ${ }^{[9]}$ medicine, ${ }^{[10]}$ dentistry ${ }^{[11]}$ and physiotherapy. ${ }^{[12]}$

However, human beings are born to understand and perceive the world with five basic senses. They are sight, taste, touch, hearing and smell. Information is transmitted to the brain for processing through these senses. Neil Fleming's VARK model ${ }^{[13]}$ shares the same concept. It is a kind of learning styles model and the abbreviation VARK stands for Visual, Aural, Read/write and Kinaesthetic. He asserted that there are five different types of sensory modalities which include visual, auditory, read/write, kinaesthetic and mixed modality. Visual dominant learners prefer graphical and symbolic information, aural dominant learners prefer classroom lectures, $\mathrm{read} /$ write dominant learners prefer printed materials, and kinaesthetic dominant learners prefer experience and practice using multiple perceptual modes including sight, sound, and touch. Here, "dominant" is a crucial word. For instance, a learner may exercise more than one sensory modality in learning, but on average, he or she frequently learns with graphics. Then, this learner probably will be classified as a visual dominant learner. Such classification can be distinguished by completing the VARK questionnaire. Assuming that Neil's propositions are established, is CM only favourable for visual learners? How about those people who have other dominant sensory modalities in their learning? Can they also benefit from CM?

In this paper, 'learning style' and 'sensory modalities' are frequently used. Hence, it is better to define these two terms beforehand to avoid any confusion. 'Learning style' is an umbrella term which is broader than 'sensory modality'. It is the way that an individual prefers how to obtain and process information, experiences or skills; and then forms his/her own sets of concepts and principles. ${ }^{[14]}$ In contrast, "sensory modality' refers specifically to the subgroups, which are visual, aural, read/write, kinaesthetic and multi-modal under Fleming's VARK model.

It is known from the literature that nursing researchers have been exploring the impact of CM on students' problemsolving skills and critical thinking skills by measuring with various inventories. For instance, in Kaoshiung, Tseng et al. showed that scores in the experimental group were higher than the control group for the Critical-Thinking Scale, SelfDirected Learning Scale and Students' Performance in the Problem-Based Learning Tutorial Sessions Questionnaire. It shows that problem-based learning together with CM can en- hance students' critical thinking skills, personal accountability for self-directed learning, skills of independent study, reasoning, group interaction and active participation. ${ }^{[15]}$ However, empirical research in connection with the relationship between concept mapping and academic performance concerning the VARK model or other learning styles models is scant. Atay and Karabacak used the California Critical Thinking Disposition Inventory to measure the differences in student nurses' critical thinking ability between control and experimental groups in Turkey. The results revealed significant differences in the post-tests between these two groups, in that students who learned using CM scored significantly higher in critical thinking than those who did not. ${ }^{[16]}$ Lee et al. used the Critical Thinking Scale to measure student nurses' critical thinking at four different points in time for both control and experimental groups in Taiwan. The results showed that the experimental group gained a higher critical thinking score across time compared to the control group. ${ }^{[17]}$ Moattari et al. used the 17 dimensions of critical thinking to evaluate the differences between control and experimental groups among student nurses in Iran. They found that the experimental group performed significantly better in five out of seven areas related to cognitive thinking skills and six out of ten areas of a habit of the mind. ${ }^{[18]}$ However, the relationships between $\mathrm{CM}$ and learning styles are minimal. Therefore, this study aimed to investigate the effects of CM on students' overall academic performance among visual, auditory, read/write, kinaesthetic and multi-modal dominant learners.

\section{Methodology}

\subsection{Study design}

This was a cross-sectional quantitative study which was conducted in the spring and summer semesters of 2017. The participants were nursing students pursuing a 5-year Bachelor of Health Science (Honours) in Nursing programme in Hong Kong. They enrolled on the same medical-surgical course in which the course teachers used CM as the teaching pedagogy for the first time.

\subsection{Instrument}

In this study, the VARK version 7.8 questionnaire in English was used to identify the students' dominant sensory modalities, that is visual, aural, read/write and kinaesthetic. It was developed by Fleming in 1987 and consists of 16 questions with four choices for each question. Given that the medium of instruction in this institute is English, the target students can read and comprehend English. All the questions in the VARK questionnaire are real-life scenarios, and the participants are allowed to choose more than one if a single answer does not match their perception. Hence, the 
answers should be highly close to the participants' authentic behaviour. This is a validated tool extensively used in many countries across different disciplines. ${ }^{[20]}$ Its content validity is reliable and consistent because, during its development, the authors conducted experiments at Lincoln University for over 11 years when it was tested against the students' perceptions of themselves-the questionnaire results highly matched their own perceptions of preferences. ${ }^{[21]}$ Leite, Svinicki and Shi found that the reliability estimates for the scores of the VARK sub-scales were $0.85,0.82,0.84$, and 0.77 for the visual, aural, read/write, and kinaesthetic sub-scales, respectively. ${ }^{[22]}$ Apart from the VARK questionnaire, demographic data such as gender, age and students' overall academic performance on this course were also collected.

\subsection{Study procedure}

The VARK questionnaires were distributed with an information sheet to the students in the first lesson. A drop-in box was provided outside the classroom for collecting the returned questionnaires after the class. After receiving the returned questionnaires, the researcher entered the data into a spreadsheet and then sent it to Dr. Neil Fleming for identification of sensory modalities in terms of his VARK model because he owns the VARK research algorithm.

After the course started, the course teachers employed CM with animation in PowerPoints teaching in large class lectures to all the students. Then, tutorial sessions were held after 1-2 lectures. In the tutorial sessions, the teacher-tostudent ratio was 1:25. The 25 students were required to split into small groups, discuss scenario-based questions, and then draw a concept map to delineate the answers. At the end of the tutorials, the tutors debriefed with pre-made animated concept maps with PowerPoints. Such a teaching pattern was repeated four times throughout the semesters. After the semesters, students' overall academic performance in this course was used to compare the differences between the five sensory modality groups.

\subsection{Ethical consideration}

Ethical approval for this study was obtained from the Committee on the Use of Human and Animal Subjects in Teaching and Research of the studied institute. Besides, the Registrar's approval to use de-identified students' academic results was also obtained before the implementation of the study. Furthermore, the author's permission to use the VARK questionnaire was obtained too. To minimize contamination of the study, the researchers were not involved in teaching the course. In addition, to avoid coercion of the participants, a member of the clerical staff was assigned to distribute the VARK questionnaires in the class, and a drop-in box was provided for collecting the returned questionnaires. Implied consent was applied in this study, and students' participation in this study was absolutely voluntary.

\subsection{Data analysis}

To examine the reliability of the VARK questionnaire on this studied group, multitrait-multimethod confirmatory factor analysis (MTMM-CFA) was conducted by Mplus Version 7 to model the method effects instead of using Cronbach Alpha because Leite et al. asserted that 'Cronbach Alpha would underestimate the reliability of the VARK scores (p.33)'. ${ }^{[22]}$ Therefore, the researcher followed their work and tested the data of this study with multitrait-multimethod confirmatory factor analysis (MMTM-CFA) which includes four models. They are correlated trait-correlated method (CTCM), correlated trait-correlated uniqueness (CTCU), correlated-traituncorrelated method (CTUM) and correlated trait-correlated methods minus one (CT-C (M-1)). The results revealed that the composite reliability coefficients of the VARK subscales were $0.73,0.79,0.84$ and 0.69 for visual, aural, read/write, and kinaesthetic subscales, respectively, which means the reliability of this tool is acceptable. ${ }^{[24]}$

Although students received their final grade as an alphabetical letter, teachers were required to submit score to the Registry for conversion. In this study, the researcher used the submitted score as continuous data for analysis. IBM SPSS Version 24.0 was used to run the statistical data analysis. Standard procedures to check for coding and data entry error were implemented. Frequency count and descriptive statistics such as mean and standard deviation were used to present the characteristics of variables. In addition, independent $t$-tests were used to compare the pass rate and overall grade between the spring and summer groups. If the $p$-value is less than .05 , it means that there is a statistically significant difference between these two groups. In addition, one-way analysis of variance (ANOVA) was used to compare the overall grade between five different sensory modality groups. If the $p$-value is less than .05 , it means that there is a statistically significant difference between the groups.

\section{Results}

A total of 199 students $(M=55, F=144)$ enrolled on this medical-surgical nursing course; $109(M=31, F=78)$ were spring students and $90(M=24, F=66)$ were summer students. The age of the students ranged from 18-20 years, with a mean of 18.86 years $(S D=0.59)$. All of them were local people from Hong Kong. However, nine spring students $(8.3 \%)$ and $13(14.4 \%)$ summer students did not complete the VARK questionnaire. As a result, the overall academic performance of 100 spring students and 77 summer students 
was used for analysis. Among the spring students, there were $28(25.7 \%)$ visual learners, $15(13.8 \%)$ aural learners, two $(1.8 \%) \mathrm{read} / \mathrm{write}$ learners, $12(11 \%)$ kinaesthetic learners and $43(39.4 \%)$ multi-modal learners. Among the summer students, there were 18 (20\%) visual learners, $12(13.3 \%)$ aural learners, nine (10\%) read/write learners, nine $(9 \%)$ kinaesthetic learners, and 29 (32.2\%) multi-modal learners. When spring and summer students were combined, there were $56(26 \%)$ visual learners, $27(15 \%)$ aural learners, 11 $(6 \%) \mathrm{read} / \mathrm{write}$ learners, $21(12 \%)$ kinaesthetic learners and $72(41 \%)$ multi-modal learners.

The mean grades of the spring students were: visual $(M=$ $80.80, S D=7.30)$, aural $(M=81.49, S D=4.19)$, read/write $(M=81.16, S D=8.69)$, kinaesthetic $(M=78.27, S D=7.56)$ and multimodal $(M=79.56, S D=7.65)$. The ranking of mean grade from highest to lowest in this group was aural, $\mathrm{read} / \mathrm{write}$, visual, multi-modal and kinaesthetic. The means of overall grade of summer students were: visual $(M=74.68$, $S D=8.59)$, aural $(M=78.79, S D=9.38)$, read/write $(M$ $=74.89, S D=3.87)$, kinaesthetic $(M=77.10, S D=9.69)$ and multimodal $(M=75.96, S D=9.74)$. The ranking of mean grade from highest to lowest in this group was aural, kinaesthetic, multi-modal, read/write and visual. After comparing the average grades between different sensory modality groups in both spring and summer semesters using One-way ANOVA testing, there were no statistically significant differences found (see Table 1) even after combining the overall grades for both semesters (see Table 2).

Table 1. Differences of academic performance for each learning style in spring \& summer semesters

\begin{tabular}{|c|c|c|c|c|c|c|c|c|}
\hline & \multicolumn{4}{|c|}{$\begin{array}{l}\text { Spring Semester } \\
(\mathrm{N}=100)\end{array}$} & \multicolumn{4}{|c|}{$\begin{array}{l}\text { Summer Semester } \\
(\mathrm{N}=77)\end{array}$} \\
\hline & $n$ & $M(S D)$ & [95\% CI] & $p$ & $n$ & $M(S D)$ & [95\% CI] & $p$ \\
\hline Visual & 28 & $80.80(7.30)$ & {$[77.90,83.64]$} & & 18 & 74.68 (8.59) & {$[70.41,78.95]$} & \\
\hline Aural & & & & 1.000 & & & & .810 \\
\hline Read/write & & & & 1.000 & & & & 1.000 \\
\hline Kinaesthetic & & & & .902 & & & & .984 \\
\hline Multimodal & & & & .978 & & & & .997 \\
\hline Aural & 15 & 81.49 (4.19) & {$[79.18,83.81]$} & & 12 & 78.79 (9.38) & {$[72.83,84.76]$} & \\
\hline Visual & & & & 1.000 & & & & .810 \\
\hline Read/write & & & & 1.000 & & & & .916 \\
\hline Kinaesthetic & & & & .845 & & & & .998 \\
\hline Multimodal & & & & .943 & & & & .936 \\
\hline Read/write & 2 & 81.16 (8.69) & {$[3.14,159.18]$} & & 9 & 74.89 (3.87) & {$[71.92,77.86]$} & \\
\hline Visual & & & & 1.000 & & & & 1.000 \\
\hline Aural & & & & 1.000 & & & & .916 \\
\hline Kinaesthetic & & & & .995 & & & & .995 \\
\hline Multimodal & & & & 1.000 & & & & 1.000 \\
\hline Kinaesthetic & 12 & 78.27 (7.56) & {$[73.46,83.07]$} & & 9 & 77.10 (9.69) & {$[69.66,84.55]$} & \\
\hline Visual & & & & .902 & & & & .984 \\
\hline Aural & & & & .845 & & & & .998 \\
\hline Read/write & & & & .995 & & & & .995 \\
\hline Multimodal & & & & .993 & & & & .999 \\
\hline Multimodal & 43 & $79.56(7.65)$ & {$[77.21,81.92]$} & & 29 & $75.96(9.74)$ & {$[72.26,79.67]$} & \\
\hline Visual & & & & .978 & & & & .997 \\
\hline Aural & & & & .943 & & & & .936 \\
\hline Read/write & & & & 1.000 & & & & 1.000 \\
\hline Kinaesthetic & & & & .993 & & & & .999 \\
\hline
\end{tabular}

Note. $M$ = mean; $S D$ = standard deviation; $\mathrm{CI}$ = confidence interval 
Table 2. Differences in academic performance for each learning style in combined spring \& summer semesters $(\mathrm{N}=177)$

\begin{tabular}{|c|c|c|c|c|}
\hline & $n$ & $M(S D)$ & [95\% CI] & $p$ \\
\hline Visual & 46 & $78.41(8.30)$ & {$[75.94,80.88]$} & \\
\hline Aural & & & & .928 \\
\hline Read/write & & & & .950 \\
\hline Kinaesthetic & & & & 1.000 \\
\hline Multimodal & & & & 1.000 \\
\hline Aural & 27 & 80.29 (6.97) & {$[77.54,83.05]$} & \\
\hline Visual & & & & .928 \\
\hline Read/write & & & & .675 \\
\hline Kinaesthetic & & & & .889 \\
\hline Multimodal & & & & .835 \\
\hline Read/write & 11 & 76.03 (5.09) & {$[72.61,79.45]$} & \\
\hline Visual & & & & .950 \\
\hline Aural & & & & .675 \\
\hline Kinaesthetic & & & & .992 \\
\hline Multimodal & & & & .967 \\
\hline Kinaesthetic & 21 & 77.77 (8.32) & {$[73.98,81.56]$} & \\
\hline Visual & & & & 1.000 \\
\hline Aural & & & & .889 \\
\hline Read/write & & & & .992 \\
\hline Multimodal & & & & 1.000 \\
\hline Multimodal & 72 & 78.11 (8.67) & {$[76.07,80.15]$} & \\
\hline Visual & & & & 1.000 \\
\hline Aural & & & & .835 \\
\hline Read/write & & & & .967 \\
\hline Kinaesthetic & & & & 1.000 \\
\hline
\end{tabular}

Note. $M$ = mean; $S D$ = standard deviation; $\mathrm{CI}$ = confidence interval.

\section{Discussion}

$\mathrm{CM}$ is a common graphical teaching and learning tool which has been widely employed in education for over a decade. However, the five senses of human beings: sight, taste, touch, hearing and smell are the first entries when the information comes into contact with our brains. According to Neil's VARK model, individuals acquire sensory modality differently, and they use one or more dominantly. Therefore, this study examined whether the CM is only favourable to visual dominant learners by comparing the overall academic performance among different sensory modality groups.

The results showed that the majority of the students were multi-modal learners $(41 \%)$. This is congruent with other studies conducted in various healthcare professions. ${ }^{[14,25]}$ It may indicate that many university students are capable of managing different situations or different kinds of knowledge with different senses to obtain the best outcome or it may relate to the nature of the discipline as the same phenomenon is only found in health-related or science subjects. It may not be the case in other disciplines.

Some researchers suggest that the ideal way is for educators to identify students' learning modalities first, and then employ appropriate teaching strategies to enhance their understanding of knowledge ${ }^{[19]}$ However, in nursing education in Hong Kong, the number of students in each class is at least 100 , with some classes even up to 400 . Under these circumstances, it is challenging to implement the strategy mentioned above, but conventional lecturing is apparently insufficient to aid students' learning of complicated knowledge. The medical-surgical course of this study ran in both spring and summer semesters respectively, and both of the results showed that there are no significant differences between visual, aural, read/write, kinaesthetic and multi-modal groups in terms of their overall academic performance after learning with animated CM in PowerPoint. Although numerous studies have examined the relationships between $\mathrm{CM}$ 
and academic performance, only three studies were found concerning learning styles in the recent ten years. Kostovich et al. ${ }^{[26]}$ conducted a similar study on 120 nursing undergraduates but with Kolb's classification of learning styles. Their results showed that there were no significant differences between different learning styles in Kolb's model when students are learning with $\mathrm{CM}$. Li et al. ${ }^{[27]}$ used the Myers-Briggs type indicator to classify 285 nursing students into 16 types of personalities. The results found that their academic performance was significantly related to the learning style and the dimension of personalities. Recently, a study in Iran used pre and post-tests with 40 multiple choice questions to examine the differences among VARK groups. There were 20 students in each subgroup as there were 80 students in the test and intervention groups, respectively. The results revealed that there was a significant difference in visual learners group between the pre and post-tests but no significant differences in the others. However, it did not mention the differences of scores in the post-tests among the groups. Therefore, it is difficult to compare with this study.

Although there are controversies about learning styles/preferences because lack of robust evidence support, the VARK model is a widely accepted learning style model and indeed human beings learn the world with inherent senses. Thus, every individual has a different degree of sensitivity in senses. As a result, learners exercise their dominant sensory modality to receive information. If this argument is established, the results of this study are quite encouraging. It is because large-class teaching is a common phenomenon in higher education, and it is difficult for educators to understand each learner's learning strategy. Given that teaching with animated CM in PowerPoint likely is a universal learning tool which suitable for all kinds of learners, the quality of learning probably will be enhanced. However, a few limitations exist. Although the course coordinator and syllabus of the medical-surgical course in the spring and summer semesters are the same, a few teaching

\section{REFERENCES}

[1] Ausubel DP. The psychology of meaningful verbal learning. New York, NY: Grune and Stratton. 1963.

[2] Novak JD. Learning, creating, and using knowledge: Concept maps as facilitative tools in school and corporations. Journal of e-Learning and Knowledge Society. 2010; 6(3): 21-30.

[3] Novak JD, Gowin DB. Learning how to learn. New York, NY: Cambridge University Press; 1984.

[4] Novak JD. Concept maps and Vee diagrams: two metacognition tools to facilitate meaningful learning. Instructional Science. 1990; 19: team members and the exam questions vary. In addition, numerous individual/internal factors may also affect students' academic performance, such as motivation, self-efficacy, stress and study time. Besides, the population size of a few subgroups were pretty small such that there were only two $\mathrm{read} / \mathrm{write}$ students in spring, and nine read/write and kinaesthetic students respectively in summer. An experimental study with a larger sample size is recommended in the future.

Furthermore, in this study, the CM was delivered to students with animation in PowerPoints by lecturing, and coconstructing $\mathrm{CM}$ with classmates was required for answering scenario-based questions in tutorial sessions. This teaching strategy encompasses visual, aural, read/write and kinaesthetic stimulations. Students learned from the diagrams of $\mathrm{CM}$, listening to the teachers, reading the learning materials and composing CM in class; therefore, the results may be caused by an offset effect. It means that students in different sensory modality groups also can benefit from the learning process. Lastly, a piece of knowledge is missing. Although our senses are the first contact points when we receive knowledge from outside, after the data enter our brains, individuals may exercise different degrees of adjustment or employ various strategies to enhance their own understanding or something else. This is the part that we do not have concrete answers to yet.

\section{Conclusion}

To conclude, the results of this study show that $\mathrm{CM}$ with animation and drawing collaboratively seems applicable to learners with different sensory modalities. However, there is limited study in this area, so repeated studies in various contexts with larger populations will help to validate the arguments. Thus, an in-depth exploration of the mechanism between $\mathrm{CM}$ and the internal environment of an individual may help to explain the phenomenon further.

\section{CONFlicts OF InTEREST Disclosure}

The authors declare that there is no conflict of interest.
1-25. https://doi.org/10.1007/BF00377984

[5] Harrison S, Gibbons C. Nursing student perceptions of concept maps: From theory to practice. Nursing Education Perspective. 2013; 34(6): 395-399. PMid:24475601 https://doi .org/10.5480/10-465

[6] Moattari M, Soleimani S, Moghaddam NJ, et al. Clinical concept mapping: Does it improve discipline-based critical thinking of nursing students? Iranian Journal of Nursing and Midwifery Research 2014; 19(1): 70-76.

[7] Sarker PK. Use of concept maps for problem-solving in engineering. Global Journal of Engineering Education. 2015; 17(1): 29-33. 
[8] Tseng HC, Chou FH, Wang HH, et al. The effectiveness of problembased learning and concept mapping among Taiwanese registered nursing students. Nurse Education Today. 2011; 31(8): 41-46. PMid:21159411 https ://doi.org/10.1016/j.nedt.2010.11 .020

[9] Bressington DT, Wong WK, Lam KKC, et al. Concept mapping to promote meaningful learning, help relate theory to practice and improve learning self-efficacy in Asian mental health nursing students: A mixed-methods pilot study. Nurse Education Today. 2018; 60: 4755. PMid:29028566 https : //doi .org/10.1016/j . nedt . 2017. 09.019

[10] Urval RP, Kamath A, Ullal S, et al. Assessment of learning styles of undergraduate medical nursing students using a VARK questionnaire and the influence of sex and academic performance. Advances in Physiology Education. 2014; 38: 216-220. PMid:25179610 https://doi.org/10.1152/advan.00024.2014

[11] Kinchin IM, Cabot LB. An introduction to concept mapping in dental education: the case of partial denture design. European Journal of Dental Education. 2009.

[12] Montpetit-Tourangeau K, Dyer J, Hudon A, et al. Fostering clinical reasoning in physiotherapy: comparing the effects of concept map study and concept map completion after example study in novice and advanced learners. BMC Medical Education. 2017; 17: 238. PMid:29191189 https ://doi .org/10.1186/s12909-017-107 $6-z$

[13] Fleming ND, Mills C. Not another inventory, rather a catalyst for reflection. To Improve the Academy. 1992; 11: 137-155. https : //doi.org/10.1002/j.2334-4822.1992.tb00213.x

[14] Othman N, Amiruddin MH. Different perspectives of learning styles from VARK model. Procedia Social and Behavioral Sciences. 2010; 7: 652-660. https://doi.org/10.1016/j.sbspro.2010.10.0 88

[15] Tseng HC, Chou FH, Wang HH, et al. The effectiveness of problembased learning and concept mapping among Taiwanese registered nursing students. Nurse Education Today. 2011; 31(8): 41-46. PMid:21159411 https ://doi.org/10.1016/j.nedt.2010.11 .020

[16] Atay S, Karabacak Ü. Care plans using concept maps and their effects on the critical thinking dispositions of nursing students. International Journal of Nursing Practice. 2012; 18: 233-239. PMid:22621292 https://doi.org/10.1111/j.1440-172X.2012.02034.x
[17] Lee W, Chiang CH, Liao IC, et al. The longitudinal effect of concept map teaching on critical thinking of nursing students. Nurse Education Today. 2013; 33: 1219-1223. PMid:22795871 https : //doi.org/10.1016/j.nedt.2012.06.010

[18] Moattari M, Soleimani S, Moghaddam NJ, et al. Clinical concept mapping: Does it improve discipline-based critical thinking of nursing students? Iranian Journal of Nursing and Midwifery Research. 2014; 19(1): 70-76.

[19] Schmeck RR. Learning strategies and learning styles. New York, NY: Springer; 2013.

[20] Khanal L, Shah S, Koirala S. Exploration of preferred learning styles in medical education using VARK modal. Russian Open Medical Journal. 2014; 3. https : //doi .org/10.15275/rusomj . 2014 . 0 305

[21] Fleming ND. Teaching and learning styles: VARK strategies. 2010. Available from: http://vark-learn.com/product/teachin g-and-learning-styles/

[22] Leite WL, Svinicki M, Shi Y. Attempted validation of the scores of the VARK: Learning styles inventory with multitrait-multimethod confirmatory factor analysis models. Educational and Psychological Measurement. 2010; 70(2): 323-339. https ://doi.org/10.117 7/0013164409344507

[23] Muthén LK, Muthén BO. Mplus User's Guide. 7th ed. Los Angeles, CA: Muthén \& Muthén. 2012.

[24] Wong SWJ, Chin CWK. Reliability of the VARK questionnaire in Chinese nursing undergraduates. US-China Education Review. 2018; 8(8): 332-340. https://doi.org/10.17265/2161-623X/2018 .08 .002

[25] Meehan-Andrews TA. Teaching mode efficiency and learning preferences of first year nursing students. Nurse Education Today. 2009; 29: 24-32. PMid:18757118 https ://doi.org/10.1016/j.nedt .2008 .06 .007

[26] Kostovich CT, Poradzisz M, Wood K, et al. Learning style preference and student aptitude for concept maps. The Journal of Nursing Education. 2007; 46(5): 225-231. PMid:17547346 https: //doi.org/10.3928/01484834-20070501-06

[27] Li YS, Yu WP, Liu CF, et al. An exploratory study of the relationship between learning styles and academic performance among students in different nursing programs. Contemporary Nurse. 2014; 48(2): 229 239. https://doi.org/10.1080/10376178.2014.11081945 